\title{
Frequency of Hypogonadism in Type 2 Diabetes Mellitus Patients with and without Coronary Artery Disease
}

Muhammad T. Raza ${ }^{1}$, Sabira Sharif ${ }^{1}$, Zohaib Ahmad Khan ${ }^{2}$, Sadaf Naz ${ }^{1}$, Samsam Mushtaq ${ }^{1}$, Amina Umer ${ }^{1}$

1. Medicine, Allama Iqbal Medical College//innah Hospital, Lahore, PAK 2. Internal Medicine, Shaikh Zayed Hospital, Lahore, PAK

Corresponding author: Muhammad T. Raza, tabish1975@hotmail.com

\section{Abstract}

\section{Introduction}

Hypogonadism is characterized by clinical and biochemical evidence of testosterone deficiency. Low testosterone levels have been reported in patients with type 2 diabetes mellitus (T2DM), which can predispose to coronary artery disease (CAD). It has been proposed that diabetic men with proven CAD have lower androgen levels than patients with normal coronary arteriograms. We conducted this study with the objective to determine the frequency of hypogonadism in patients with diabetes mellitus and its relationship with CAD.

\section{Materials and Methods}

It was a comparative cross-sectional study conducted at a tertiary care hospital. We recruited a total of 108 patients, divided into two groups, 54 patients in each arm of the study. Group A comprised patients with $\mathrm{CAD}$, whereas group $\mathrm{B}$ consisted of diabetic patients without CAD. Hypogonadism was defined on the basis of erectile dysfunction clinically and total testosterone levels biochemically. CAD was diagnosed on the basis of findings of coronary angiography. Fasting blood samples were drawn and evaluated for fasting plasma glucose, HbA1c, fasting lipid profile, thyroid-stimulating hormone (TSH), serum prolactin, blood urea, serum creatinine, liver function tests (LFT), total testosterone, luteinizing hormone (LH), and follicle-stimulating hormone (FSH) levels. Hypogonadism among two study groups was compared using chisquare and serum testosterone level was compared using independent $t$-test with $p<0.05$ considered as statistically significant.

\section{Results}

There were 108 subjects in the study with the mean age of $54.4 \pm 4.29$ (range: 22 to 68 ) years. The mean duration of T2DM was $12.6 \pm 8.2$ years. The mean BMI of patients with and without CAD was $25.7 \pm 2.37$ and

Received 12/19/2019

Review began 12/25/2019 Review ended 12/26/2019 Published 12/29/2019

\section{() Copyright 2019}

Raza et al. This is an open access article distributed under the terms of the Creative Commons Attribution License CC-BY 3.0., which permits unrestricted use, distribution, and reproduction in any medium, provided the original author and source are credited.
$26.9 \pm 4.21 \mathrm{~kg} / \mathrm{m}^{2}$, respectively. There was no significant difference in waist circumference and obesity between both the groups ( $p$-value $>0.05$ ). Fasting plasma glucose and HbA1c in both groups were not significantly different. Testosterone levels and erectile dysfunction score were found lower in T2DM with CAD compared to T2DM patients without CAD, although this difference was not statistically significant ( $p$ value: 0.051 ). The majority of the subjects with hypogonadism in both groups had a hypogonadotrophic hypogonadism (39/42, 92.9\% versus 16/20, 80.0\%). No statistically significant difference was seen in serum levels of LH and FSH between the study groups. The frequency of hypogonadism was found higher in the group with $\mathrm{CAD}(72.2 \%, 39 / 54)$ as compared with $\mathrm{T} 2 \mathrm{DM}$ patients without $\mathrm{CAD}(37.03 \%, 20 / 54 ; p$-value = $0.000)$.

\section{Conclusion}

Testosterone deficiency is a significant problem of males with T2DM. Patients with CAD have markedly low levels of testosterone as compared with patients without any CAD.

Categories: Endocrinology/Diabetes/Metabolism, Internal Medicine

Keywords: hypogonadism, frequency, coronary artery disease, diabetes mellitus, testosterone, deficiency

\section{Introduction}

Hypogonadism is a clinical condition comprising both clinical and biochemical evidence of testosterone deficiency [1-3]. Males with type 2 diabetes mellitus (T2DM) have low testosterone levels in comparison to healthy individuals [4]. The reported prevalence of hypogonadism in different studies varies from $11.8 \%$ to $97.2 \%$ primarily due to differences in diabetic control in the study population [4-5]. 
There are multiple causes of low testosterone level in T2DM patients, which include decreased production of sex hormone-binding globulin (SHBG) by liver, which is a major carrier protein of testosterone in circulation [2]. Furthermore, visceral obesity among diabetics converts testosterone to estradiol by aromatase enzyme in adipose tissues. Low testosterone, in turn, leads to even more fat accumulation and augmentation of testosterone deficiency [6-7].

Framingham heart study suggests that low testosterone level increases the risk of coronary artery disease (CAD) [7]. Low testosterone level modifies cardiovascular risk factors particularly lipid profile, blood pressure, obesity, insulin resistance, inflammatory cytokines \& fibrinogen levels, all of which are risk factors of CAD [8]. Testosterone also has vasoactive properties improving both systemic and coronary blood flow [7]. The effect of low testosterone on CAD remains significantly high even after adjustment of other confounding variables of CAD, including age, obesity, and dyslipidemia, which are also significant predictors of CAD in men with or without T2DM [9]. It has also been reported that diabetic men with proven $\mathrm{CAD}$ have lower androgen levels than patients with normal coronary arteriograms [10].

Although testosterone deficiency has proven to be a risk factor for $\mathrm{CAD}$, this has received scant attention in the medical literature. So, we conducted this study with the objective to determine the frequency of hypogonadism in T2DM and its variation with regard to CAD.

\section{Materials And Methods}

It was a comparative cross-sectional study conducted at (redacted for peer review) from August 2018 to April 2019. This study was approved by the Ethical Review Board of (redacted for peer review). We recruited a total of 108 patients, divided into two groups, with 54 patients in each arm of the study. Group A comprised patients with $C A D$, whereas group $B$ consisted of patients without CAD. Patients were labeled to have T2DM if they fulfilled one or more of the following criteria of the American Diabetic Association (ADA) [11-12].

1. Fasting blood sugar $(\mathrm{FBS}) \geqslant 126 \mathrm{mg} / \mathrm{dl}(7 \mathrm{mmol} / \mathrm{L})$ after eight hours of fasting

\section{2. $\mathrm{HBA} 1 \mathrm{c} \geqslant 6.5 \%$}

3. Random blood sugar (RBS) $\geqslant 200 \mathrm{mg} / \mathrm{dl}(11.1 \mathrm{mmol} / \mathrm{L})$ with symptoms of hyperglycemia (polydipsia, polyuria, polyphagia, and weight loss).

4. Two-hour RBS $\geqslant 200 \mathrm{mg} / \mathrm{dl}(11.1 \mathrm{mmol} / \mathrm{L})$ on $75 \mathrm{~g}$ oral glucose tolerance test (OGTT)

Erectile dysfunction was labeled on the basis of the International Index of Erectile Dysfunction (IIEF) score. Patients with score less than 20 were diagnosed to be suffering from erectile dysfunction. Patients with total testosterone (TT) level below $3 \mathrm{ng} / \mathrm{ml}$ were diagnosed as having hypogonadism and were sub-categorized as mentioned below:

1. Hypogonadotropic hypogonadism (HH) was defined as TT level $<3 \mathrm{ng} / \mathrm{ml}$ and luteinizing hormone (LH) values $\leqslant 10 \mathrm{IU} / \mathrm{L}$.

2. Primary hypogonadism was defined as TT levels $<3 \mathrm{ng} / \mathrm{ml}$ and LH levels $>10 \mathrm{IU} / \mathrm{L}$.

The following patients were excluded from the study:

1. Patients with type 1 diabetes mellitus

2. With a known history of hypogonadism, hyperprolactinemia/ prolactinoma, or panhypopituitarism, Klinefelter syndrome, cryptorchidism, varicocele, and any other disorder of androgen synthesis

3. Past history of any coronary event (myocardial infarction or unstable angina) or coronary procedure (coronary artery bypass or coronary angioplasty) in the previous four weeks

4. Liver disease (bilirubin $\geqslant 1.5 \mathrm{mg} / \mathrm{dl}$ ), serum creatinine levels $>1.5 \mathrm{mg} / \mathrm{dl}$

5. Systemic disorders such as cancer, epilepsy, hypothyroidism, and evidence of any active infection

6. Alcoholics ( $\geqslant 500 \mathrm{ml} /$ week of alcohol for $\geqslant 6$ months period)

7. Acute stress, anorexia nervosa, and malnutrition

8. History of mumps, radiation, alkylating agents, ketoconazole, glucocorticoid use, trauma 
Group A - T2DM subjects with confirmed CAD by either one of prior coronary angiography or computed tomography (CT) angiography were included in this group. They were enrolled from the cardiology outpatients department under the supervision of the experienced cardiologist. Group B - T2DM subjects without CAD were enrolled from the Jinnah hospital Endocrinology department (JAIDE).

Patients were assured that all the information would be kept confidential and patient's privacy would not be affected. After obtaining written informed consent from the patients, a biodata form was filled and detailed medical history and clinical examination were undertaken. Various parameters such as body mass index (BMI) and blood pressure (in sitting and standing postures) were recorded.

All the patients were given translated IIEF questionnaire, and erectile dysfunction was labeled as per operational definition. Fasting blood samples was drawn and sent to the hospital laboratory for analysis of plasma glucose, HbA1c, fasting lipid profile, thyroid-stimulating hormone (TSH), serum prolactin, blood urea, serum creatinine, liver function tests (LFT), total testosterone, luteinizing hormone, and follicle-stimulating hormone (FSH). Effect modifiers such as age and BMI were addressed through the stratification of data.

The data were entered and analyzed through Statistical Package for Social Sciences (SPSS version 23.0, IBM Statistics, Chicago, IL, USA). Quantitative variables such as age, serum HbA1c, total testosterone, and IIEF score were calculated as mean $\pm \mathrm{SD}$. Categorical variables such as hypogonadism and presence of CAD were analyzed as frequencies and percentages. Hypogonadism among two groups was compared using chi-square test and serum testosterone level was compared using independent $t$-test with $p<0.05$ considered as statistically significant.

\section{Results}

There were 108 subjects in the study with a mean age of patients with CAD was $54.4 \pm 4.29$ (range: 22-68) years. $55.94 \pm 4.14$ (range: $48-68$ ) years \& without CAD $52.77 \pm 4.44$ (range: $22-60$ ) years. The mean duration of T2DM was $12.6 \pm 8.2$ years. The mean BMI of patients with and without CAD was $25.7 \pm 2.37$ and $26.9 \pm$ $4.21 \mathrm{~kg} / \mathrm{m}^{2}$, respectively. Various clinical and biochemical parameters of the patients are presented in Table 1. 


\section{Cureus}

\begin{tabular}{|c|c|c|c|}
\hline \multirow{2}{*}{ Parameters } & \multicolumn{2}{|l|}{ Study Groups } & \multirow{2}{*}{ P-value } \\
\hline & With CAD (Mean \pm SD) & Without CAD (Mean $\pm S D$ ) & \\
\hline Age (years) & $55.9 \pm 4.1$ & $52.8 \pm 4.5$ & 0.090 \\
\hline Body mass index $\left(\mathrm{kg} / \mathrm{m}^{2}\right)$ & $25.7 \pm 2.4$ & $26.9 \pm 4.2$ & 0.060 \\
\hline Erectile dysfunction score & $8.74 \pm 2.8$ & $10.8 \pm 2.3$ & 0.000 \\
\hline Testosterone level (ng/ml) & $2.59 \pm .5$ & $2.89 \pm .7$ & 0.051 \\
\hline Luteinizing hormone (ng/ml) & $8.19 \pm 1.5$ & $7.46 \pm 2.7$ & 0.090 \\
\hline Follicle-stimulating hormone (ng/ml) & $7.37 \pm 2.2$ & $7.69 \pm 2.4$ & 0.467 \\
\hline Thyroid-stimulating hormone (ng/ml) & $2.96 \pm 1.2$ & $2.81 \pm .8$ & 0.420 \\
\hline Prolactin levels (ng/ml) & $8.65 \pm 3.8$ & $10.9 \pm 1.9$ & 0.000 \\
\hline Fasting blood sugar (mg/dl) & $143 \pm 16.9$ & $149 \pm 20.3$ & 0.151 \\
\hline HBA1c (\%) & $10.6 \pm 1.8$ & $10.8 \pm 1.9$ & 0.74 \\
\hline Serum cholesterol (mg/dl) & $205 \pm 13.5$ & $205 \pm 19.3$ & 0.822 \\
\hline Low Density Lipoprotein (mg/dl) & $103 \pm 10.5$ & $108 \pm 17.1$ & 0.116 \\
\hline High density lipoprotein (mg/dl) & $37.1 \pm 3.2$ & $37.7 \pm 4.1$ & 0.399 \\
\hline Serum triglyceride (mg/dl) & $184 \pm 19.9$ & $166 \pm 15.8$ & 0.000 \\
\hline Blood urea (mg/dl) & $17.7 \pm 5.4$ & $23.5 \pm 5.0$ & 0.000 \\
\hline Serum creatinine (mg/dl) & $1.02 \pm .1$ & $1.05 \pm .8$ & 0.834 \\
\hline Systolic blood pressure $(\mathrm{mmHg})$ & $134 \pm 12.4$ & $129 \pm 20.3$ & 0.108 \\
\hline Diastolic blood pressure (mmHg) & $83.9 \pm 4.5$ & $82.7 \pm 7.9$ & 0.354 \\
\hline
\end{tabular}

\section{TABLE 1: Clinical and biochemical parameters of the study population}

CAD, coronary artery disease; HbA1c, glycated hemoglobin A1c

Subjects in both groups were matched for age and BMIs. Table 2 shows the frequency of hypogonadism and erectile dysfunction in patients with and without CAD. 


\section{Cureus}

\begin{tabular}{|c|c|c|c|c|}
\hline \multirow{2}{*}{ Parameter } & & \multicolumn{2}{|c|}{ Coronary artery disease } & \multirow{2}{*}{ P-value } \\
\hline & & Present & Absent & \\
\hline \multirow{4}{*}{ Hypoganadism } & & 39 & 20 & \multirow{4}{*}{0.000} \\
\hline & & $72.2 \%$ & $37.0 \%$ & \\
\hline & \multirow{2}{*}{ No } & 15 & 34 & \\
\hline & & $27.8 \%$ & $63.0 \%$ & \\
\hline \multirow{4}{*}{ Erectile dysfunction } & & 40 & 21 & \multirow{4}{*}{0.000} \\
\hline & & $74.1 \%$ & $38.9 \%$ & \\
\hline & \multirow{2}{*}{ No } & 14 & 33 & \\
\hline & & $25.9 \%$ & $61.1 \%$ & \\
\hline
\end{tabular}

TABLE 2: Frequency of hypogonadism and erectile dysfunction in the study population

There was no statistically significant difference in waist circumference and obesity between both groups ( $p$ value > 0.05). Fasting plasma glucose and HbA1c levels in both groups were not statistically different.

Testosterone and IIEF scores were found lower in T2DM with CAD compared to T2DM patients without CAD, although this difference was not statistically significant ( $p$-value: 0.051$)$. The majority of the subjects with hypogonadism in both groups had $\mathrm{HH}(39 / 42,92.9 \%$ versus $16 / 20,80.0 \%)$. No statistically significant difference was seen in serum levels of LH and FSH between the study groups ( $p$-value $>0.05$ ).

The frequency of hypogonadism as indicated by low testosterone levels \& IIEF score was found higher in Group A patients with CAD $(72.2 \%, 39 / 54)$ compared to T2DM patients without CAD $(37.03 \%$, 20/54; $p$ value $=0.000$ ).

The relationship between hypogonadism and CAD in patients with different age groups and $\mathrm{BMI}$ is presented in Tables 3 and 4 , respectively. 


\section{Cureus}

\begin{tabular}{|c|c|c|c|c|c|c|}
\hline \multirow{2}{*}{ Age groups } & \multirow{2}{*}{\multicolumn{2}{|c|}{ Presence or absence of hypogonadism }} & \multicolumn{2}{|c|}{ Study groups } & \multirow{2}{*}{ Total } & \multirow{2}{*}{ P-value } \\
\hline & & & With CAD & Without CAD & & \\
\hline \multirow{6}{*}{$<50$ years } & & & 4 & 5 & 9 & \multirow{6}{*}{0.026} \\
\hline & & & $100.0 \%$ & $31.3 \%$ & $45.0 \%$ & \\
\hline & & & 0 & 11 & 11 & \\
\hline & & NNO & $0.0 \%$ & $68.8 \%$ & $55.0 \%$ & \\
\hline & \multirow{2}{*}{ Total } & & 4 & 16 & 20 & \\
\hline & & & $100.0 \%$ & $100.0 \%$ & $100.0 \%$ & \\
\hline \multirow{7}{*}{$>50$ years } & & & 35 & 15 & 50 & \multirow{7}{*}{0.004} \\
\hline & & & $70.0 \%$ & $39.5 \%$ & $56.8 \%$ & \\
\hline & Hypogonadism & & & & & \\
\hline & & & 15 & 23 & 38 & \\
\hline & & m & $30.0 \%$ & $60.5 \%$ & $43.2 \%$ & \\
\hline & \multirow{2}{*}{ Total } & & 50 & 38 & 88 & \\
\hline & & & $100.0 \%$ & $100.0 \%$ & $100.0 \%$ & \\
\hline
\end{tabular}

TABLE 3: Relationship between age and hypogonadism in patients with and without coronary artery disease

$C A D$, coronary artery disease 


\section{Cureus}

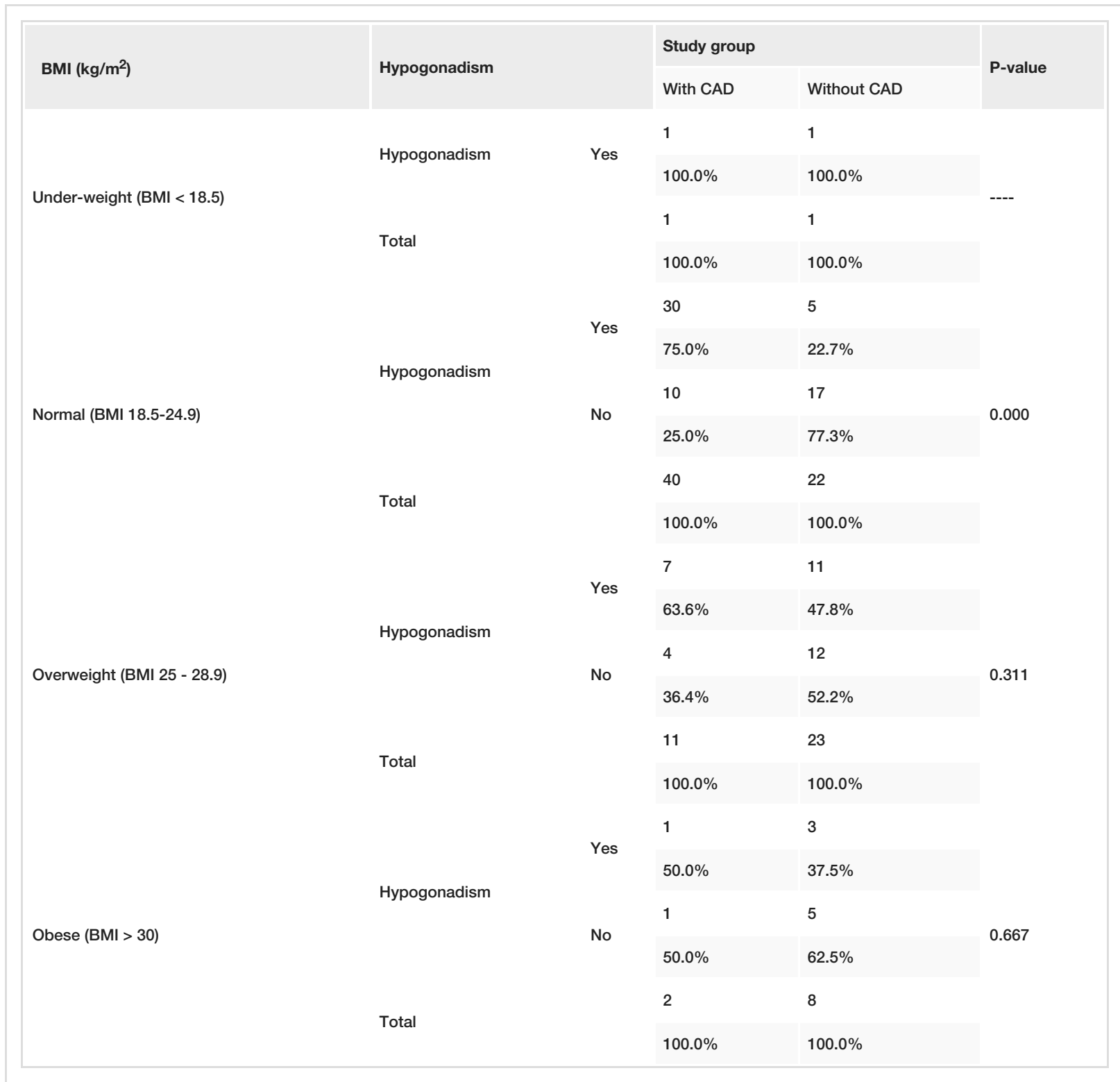

TABLE 4: Relationship between hypogonadism and coronary artery disease in patients with different body mass indices

$\mathrm{BMI}$, body mass index; CAD, coronary artery disease

\section{Discussion}

In this study, we compared the frequency of testosterone profile of diabetic patients with and without CAD. We found a significantly higher prevalence of hypogonadism in diabetic subjects with CAD compared to diabetic subjects without CAD. Madhu et al. evaluated the prevalence of hypogonadism in T2DM and its relationship with CAD [1]. In their study, hypogonadism was found to be highest in T2DM patients with CAD $(40 \%, 20 / 50)$ as compared to T2DM patients who did not have CAD (32\%, 16/50; $p$-value: 0.53$)$. The levels of total testosterone were significantly lower in patients with CAD than without CAD $(3.55 \pm 1.46 \mathrm{ng} / \mathrm{ml}$ vs. 4.73 $\pm 2.17 \mathrm{ng} / \mathrm{ml} ; P=0.005)$. They reported a positive correlation between hypogonadism and CAD $(r=0.177, P=$ 0.030 ). We also found similar results and observed greater frequency of CAD patients with hypogonadism and lower testosterone levels.

Hypogonadism occurs due to microvascular complications of diabetes and range from vasculopathy to neuropathy and endocrinal disorders. Certain studies have attributed psychogenic involvement to be the leading cause of erectile dysfunction in patients with hypogonadism. Previous studies attribute vasculopathy to be a more common culprit in causing erectile dysfunction and endocrine imbalance to be the leading cause of hypogonadism in diabetes mellitus. 
Hypogonadotropic hypogonadism was observed in most of the patients of our study as reported earlier in another study [1]. Earlier reports have shown both higher and lower testosterone levels in hypogonadotropic male diabetic patients [11]. The proposed mechanism of this observation is a higher rate of conversion of serum testosterone to estradiol in patients with higher body fat content that occurs in patients with low testosterone levels [12]. The resultant suppression of gondatotrophin-releasing hormone ( $\mathrm{GnRH})$ axis leads to hypogonadotropic hypogonadism. On the contrary, primary hypogonadism is proposed to result from microvascular lesions in the testis, which damages the interstitium of the testis.

Deleterious cardiovascular effects of low testosterone levels have earlier been reported in various studies. A study showed a higher frequency of atherosclerosis and a greater presence of inflammatory markers in patients with low testosterone levels. An earlier report also showed increased thickness of the carotid intima-media layer in patients with low testosterone levels [13].

Whether testosterone deficiency should be corrected in patients with hypogonadism still remains a controversial topic. It has been proposed that testosterone replacement therapy can reduce all-cause cardiovascular mortality in patients with CAD. A recent retrospective study reported that testosterone therapy, in an attempt to normalize testosterone levels, resulted in significant lowering of the risk of myocardial infarction and stroke in the study population [14]. Different other studies have also shown that normalizing testosterone levels in hypogonadotropic males produce improvement in glycemic control by reducing insulin resistance. The study proposed that the effect of testosterone on cardiovascular mortality is due to its indirect effect by improving glycemic control and hence, reducing the prevalence of diabetic microvascular complications [15]. We recommend future studies to determine the effect of testosterone therapy on the cardiovascular system and see if it adds to an additional cardiovascular benefit to the treated patients [16-26].

\section{Conclusions}

Testosterone deficiency is a significant problem of males with T2DM. Patients with CAD have markedly low levels of testosterone as compared with patients without any evidence of cardiovascular disease.

\section{Additional Information}

\section{Disclosures}

Human subjects: Consent was obtained by all participants in this study. Insitituional Review Board of Allama Iqbal Medical College/Jinnah Hospital, Lahore, Pakistan issued approval ERB/2018-38591. The study was approved by the Ethical Review Board of Allama Iqbal Medical College/Jinnah Hospital, Lahore, Pakistan. Animal subjects: All authors have confirmed that this study did not involve animal subjects or tissue. Conflicts of interest: In compliance with the ICMJE uniform disclosure form, all authors declare the following: Payment/services info: All authors have declared that no financial support was received from any organization for the submitted work. Financial relationships: All authors have declared that they have no financial relationships at present or within the previous three years with any organizations that might have an interest in the submitted work. Other relationships: All authors have declared that there are no other relationships or activities that could appear to have influenced the submitted work.

\section{References}

1. Madhu SV, Aslam M, Aiman AJ, Siddiqui A, Dwivedi S: Prevalence of hypogonadism in male type 2 diabetes mellitus patients with and without coronary artery disease. Indian J Endocrinol Metab. 2017, 21:31-37. 10.4103/2230-8210.195999

2. Kapoor D, Aldred H, Clark S, Channer KS, Jones TH: Clinical and biochemical assessment of hypogonadism in men with type 2 diabetes: correlations with bioavailable testosterone and visceral adiposity. Diabetes Care. 2007, 30:911-7. 10.2337/dc06-1426

3. Alkamel A, Shafiee A, Jalali A, Boroumand M, Nozari Y: The association between premature coronary artery disease and level of testosterone in young adult males. Arch Iran Med. 2014, 17:545-50.

4. Afkhamizadeh M, Ghaderian SB, Rajabian R, Aleali AM: Prevalence of hypogonadotropic hypogonadism in type 2 diabetes male patients. Open J Endocr Metab Dis. 2015, 5:29-36. 10.4236/ojemd.2015.53004

5. Ahmed I, Aamir Au, Anwar E, Ali SS, Ali A, Ali A: Erectile dysfunction and type 2 diabetes mellitus in northern Pakistan. J Pak Med Assoc. 2013, 63:1486-90.

6. Kapoor D, Malkin CJ, Channer KS, Jones TH: Androgens, insulin resistance and vascular disease in men . Clin Endocrinol. 2005, 63:239-250. 10.1111/j.1365-2265.2005.02299.x

7. Magnani JW, Moser CB, Murabito JM, et al.: Association of sex hormones, aging, and atrial fibrillation in men: the Framingham Heart Study. Circ Arrhythm Electrophysiol. 2014, 7:307-12. 10.1161/CIRCEP.113.001322

8. Kalinchenko SY, Kozlov GI, Gontcharov NP, Katsiya GV: Oral testosterone undecanoate reverses erectile dysfunction associated with diabetes mellitus in patients failing on sildenafil citrate therapy alone. Aging Male. 2009, 6:94-99. 10.1080/tam.6.2.94.99

9. Rosano GM, Sheiban I, Massaro R, et al.: Low testosterone levels are associated with coronary artery disease in male patients with angina. Int J Impot Res. 2007, 19:176-18. 10.1038/sj.ijir.3901504

10. English KM, Mandour O, Steeds RP, Diver MJ, Jones TH, Channer KS: Men with coronary artery disease have lower levels of androgens than men with normal coronary angiograms. Eur Heart J. 2000, 21:890-4. 
10.1053/euhj.1999.1873

11. Wang C, Jackson G, Jones TH, et al.: Low testosterone associated with obesity and the metabolic syndrome contributes to sexual dysfunction and cardiovascular disease risk in men with type 2 diabetes. Diabetes Care. 2011, 34:1669-1675. 10.2337/dc10-2339

12. Punthakee Z, Goldenberg R, Katz P: Definition, classification and diagnosis of diabetes, prediabetes and metabolic syndrome. Can J Diabetes. 2018, 42:S10-5. 10.1016/j.jcjd.2017.10.003

13. Khaw KT, Dowsett M, Folkerd E, et al.: Endogenous testosterone and mortality due to all causes, cardiovascular disease, and cancer in men: European Prospective Investigation into Cancer in Norfolk (EPICNorfolk) Prospective Population Study. Circulation. 2007, 116:2694-27. 10.1161/CIRCULATIONAHA.107.719005

14. Sharma R, Oni OA, Gupta K, et al.: Normalization of testosterone level is associated with reduced incidence of myocardial infarction and mortality in men. Eur Heart J. 2015, 36:2706-15. 10.1093/eurheartj/ehv346

15. Kapoor D, Goodwin E, Channer KS, Jones TH: Testosterone replacement therapy improves insulin resistance, glycaemic control, visceral adiposity and hypercholesterolaemia in hypogonadal men with type 2 diabetes. Eur J Endocrinol. 2006, 154:899-906. 10.1530/eje.1.02166

16. Javaid U, Ali MH, Jamal S, Butt NH: Pathophysiology, diagnosis, and management of glaucoma associated with Sturge-Weber syndrome. Int Ophthalmol. 2018, 38:409-16. 10.1007/s10792-016-0412-3

17. Butt NH, Ayub MH, Ali MH: Challenges in the management of glaucoma in developing countries . Taiwan J Ophthalmol. 2016, 6:119-22. 10.1016/j.tjo.2016.01.004

18. Jamal S, Ali MH, Ayub MH, Butt NH: Frequency and grading of diabetic retinopathy in diabetic end stage renal disease patients. Pak J Ophthalmol. 2016, 32:64-9.

19. Bashir ZS, Ali MH, Anwar A, Ayub MH, Butt NH: Femto-LASIK: the recent innovation in laser assisted refractive surgery. J Pak Med Assoc. 2017, 67:609-15.

20. Ali MH, Javaid M, Jamal S, Butt NH: Femtosecond laser assisted cataract surgery, beginning of a new era in cataract surgery. Oman J Ophthalmol. 2015, 8:141-6. 10.4103/0974-620X.169892

21. Ali MH, Ullah S, Javaid U, Javaid M, Jamal S, Butt NH: Comparison of characteristics of femtosecond laserassisted anterior capsulotomy versus manual continuous curvilinear capsulorrhexis: a meta-analysis of 5year results. J Pak Med Assoc. 2017, 67:1574-9.

22. Ali MH, Berry S, Qureshi A, Rattanalert N, Demer JL: Decompensated esophoria as a benign cause of acquired esotropia. Am J Ophthalmol. 2018, 194:95-100. 10.1016/j.ajo.2018.07.007

23. Ali MH, Jamal S, Rashid MA, Javaid U, Butt NH: Moebius syndrome with hypoglossal palsy, syndactyly, brachydactyly, and anisometropic amblyopia. Cureus. 2018, 10:e2334. 10.7759/cureus.2334

24. Ayub A, Akhtar FM, Saleem N, Ali MH, Ayub MH, Butt NH: Frequency and risk factors of dry eye disease in Pakistani population, a hospital based study. Pak J Ophthalmol. 2017, 33:196-203.

25. Ali MH, Pineles SL, Velez FG, Tandon AK, Glasgow BJ: Pathologic study of supernumerary orbital band in type I Duane syndrome. Ocul Oncol Pathol. 2019, 5:305-11. 10.1159/000496689

26. Hafeez MU, Ali MH, Najib N, et al.: Ophthalmic manifestations of acute leukemia . Cureus. 2019, 11:e3837. 10.7759/cureus.3837 